\title{
In vitro Degradation of Poly-L-co-D, L-lactic Acid Membranes
}

\author{
Grazielle Baraúna $^{\mathrm{a}}$ Débora Cristina Coraça-Huber ${ }^{\mathrm{b} *}$, Eliana Aparecida de Rezende Duek ${ }^{\mathrm{a}, \mathrm{c}}$ \\ ${ }^{a}$ Mechanical Engineering Faculty, State University of Campinas - UNICAMP, Campinas, SP, Brazil \\ ${ }^{\mathrm{b}}$ Experimental Orthopedics, Medical University Innsbruck, Austria \\ ${ }^{\mathrm{c} B i o m a t e r i a l s ~ L a b o r a t o r y, ~ C e n t e r ~ o f ~ M e d i c a l ~ a n d ~ B i o l o g i c a l ~ S c i e n c e ~-~ C C M B, ~}$ \\ Pontifical Catholic University of São Paulo - PUC-SP, \\ Sorocaba, SP, Brazil
}

Received: March 27, 2012; Revised: September 10, 2012

\begin{abstract}
Poly-L-co-D.L-lactic (PLDLA) is a bioresorbable polymer whose properties have been studied for degradation sensitivity and its application in medicine. In this study, the potential of PLDLA membranes for temporary implantation was evaluated. PLDLA membranes were prepared with the solvent evaporation technique and characterized by differential scanning calorimetry, gel permeation chromatography, thermogravimetric analysis, scanning electron microscopy and traction tests. The glass transition temperature of the membranes was $59^{\circ} \mathrm{C}$. Degradation started around $340{ }^{\circ} \mathrm{C}$ during the second week showing pores and fissures on the broken surface. Evident degradation was observed after 16 weeks. Microscopy showed that before degradation PLDLA membranes presented no pores. PLDLA properties of resistance to traction and elasticity module were maintained until the $8^{\text {th }}$ week, and after the $16^{\text {th }}$ week there was a sharp reduction of these properties due to degradation. PLDLA membranes present excellent potential as temporary implantation given their degradation characteristics.
\end{abstract}

Keywords: poly-L-co-D,L-lactic acid, membranes, degradation

\section{Introduction}

In the last few decades, the demand of higher quality of life and longevity has guided intensive research on the field of implantable materials and artificial organs. In this way, biomaterials have been tested for physical and mechanical properties that can be more appropriate for application in the human body, for example as surgical suture, systems for controlled release of drugs, artificial skin, artificial veins and blood vessels, orthopedic devices and guides for nervous regeneration with no side effects ${ }^{1,2}$.

Poly $\alpha$-hydroxy acids are thermoplastic poly $\alpha$-esters with chemical versatility and can be easily customized into desired shapes by molding, extrusion, or solvent processing. Polymers manufactured from glycolic acid and lactic acid monomers have been extensively studied since the late 1960 s following the successful development of the first synthetic, bioresorbable glycolide-based suture material approved by the United States (US) Food and Drug Administration (FDA) ${ }^{3}$.

Intensive investigations have been carried out also with poly-L-lactic acid (PLLA) since it has excellent mechanical properties, such as traction resistance and elasticity module. However, the long period demanded for its total degradation associated to the high crystallinity of its fragments can be related to inflammatory reactions, which restrains its application ${ }^{4-5}$. Before the clinical use of a material as implant, a series of requirements are needed. It should be biocompatible, biofunctional, innocuous, easy to sterilize and it should present proper mechanical properties $^{3}$. Depending on the purpose of the application, the implantation should not be excessively complex from the

*e-mail: debora.coraca-huber@i-med.ac.at surgical point of view. The implant should be easy to handle and, whenever necessary, readily removed. Besides all of these characteristics the material use has to be economically viable as well. In an attempt to reduce reactions caused by PLLA, a combination of L-lactic and D, L-lactic monomers resulting in a poly-L-co-D, L-lactic copolymer (PLDLA) has been studied. The main characteristics of the PLDLA are the degradation rate which is relatively fast and do not generate crystalline fragments. An additional advance is its excellent mechanical ${ }^{6-7}$.

The aims of this study were the synthesis and characterization of PLDLA membranes for mechanical, thermal and morphological properties as well as the evaluation of in vitro degradation to facilitate future in vivo studies.

\section{Material and Methods}

\subsection{Membrane preparation}

Membranes of PLDLA (MM $282700 \mathrm{~g} \cdot \mathrm{mol}^{-1}$ ) in a proportion of $70: 30$ were prepared at a concentration of $2.5 \% \mathrm{~m} \cdot \mathrm{V}^{-1}$. The solvent evaporation technique was employed utilizing dichloromethane (Merck, KGaA, Darmstadt, Germany) for obtainment of membranes sizing $50 \times 30 \times 5 \mathrm{~mm}$. After complete dissolution of the copolymer, the solution was poured into a glass plate and then placed inside a glass container which had been saturated with the solvent. The membranes were vacuum-dried and stored until the start of the in vitro study. 


\subsection{In vitro study}

In order to evaluate the material behavior under the process of hydrolytic degradation, PLDLA membranes were immersed in phosphate buffer solution (PBS) pH 7 at $37{ }^{\circ} \mathrm{C}$ in screw-cap test tubes previously sterilized with $70 \%$ alcohol. After 0, 2, 4, 8, 16, 18 and 20 weeks, the membranes were removed from PBS solution, washed with distilled water and dried in a vacuum drying stove at $60{ }^{\circ} \mathrm{C}$ during 8 hours. Before and after degradation, the membranes were characterized by differential scanning calorimetry (DSC), gel permeation chromatography (GPC), thermogravimetric analysis (TGA), scanning electron microscopy (SEM) and traction tests.

Differential scanning calorimetry (DSC): The samples weighing about $10 \mathrm{mg}$ were heated from $25^{\circ} \mathrm{C}$ to $210^{\circ} \mathrm{C}$ to $10{ }^{\circ} \mathrm{C} / \mathrm{min}$ followed by isotherm for 5 minutes; then, they were cooled to $0{ }^{\circ} \mathrm{C}$ to $10{ }^{\circ} \mathrm{C} / \mathrm{min}$ followed by a 5-minute isotherm at $0{ }^{\circ} \mathrm{C}$, and then reheated to $210{ }^{\circ} \mathrm{C}$. For this test and obtainment of the curves a colorimeter (Ta Instruments 2910) was used.

Gel permeation chromatography (GPC): The numberaverage molar masses (Mn), weight-average molar masses $(\mathrm{Mw})$ and the index of polydispersity (IP) were obtained in a liquid chromatograph (CLWA-1) by using an ultrastyragel columns and a refractive index detector (Waters 410). Polystyrene standards were used for calibration and THF (tetrahydrofuran) as mobile phase.

Thermogravimetric Analysis (TGA): a Netsch STA 409C equipment was used to heat membrane samples weighing about $20 \mathrm{mg}$ at $25^{\circ} \mathrm{C}$ to $450{ }^{\circ} \mathrm{C}$ to $10{ }^{\circ} \mathrm{C} / \mathrm{min}$ under argon atmosphere.

Scanning Electron Microscopy (SEM): membrane and fracture surface samples (obtained in liquid nitrogen) were coated with gold (Sputter Coater BAL-TEC SCD 050) and analyzed with a scanning electron microscope (JEOL JXA 860) operated at $10 \mathrm{kV}$.

Mechanical traction test: samples measuring approximately $40 \mathrm{~mm}$ in length, $2.0 \mathrm{~mm}$ in width and $0.20 \mathrm{~mm}$ in thickness were submitted to traction tests in a H5KS Tinius Olsen automatic material test system with a $200 \mathrm{~N}$ load cell at $10 \mathrm{~mm} / \mathrm{min}$ speed, in compliance with ASTM D882-02 rule. Each sample was submitted to 7 tests under the same humidity $(50 \%)$ and temperature $\left(22^{\circ} \mathrm{C}\right)$ conditions.

\section{Results and Discussion}

The in vitro degradation tests proved to be an efficient alternative to in vivo studies, because he costs are lower, the process can be speeded up and the test conditions such as temperature, $\mathrm{pH}$, products and byproducts of degradation can be quantified and monitored ${ }^{2}$, besides the advantage to avoid animal tests.

\subsection{Differential Scanning Calorimetry (DSC)}

DSC curves (second heating) of PLDLA membranes immersed in buffer solution during $0,2,4,8,16,18$ and 20 week before and after in vitro degradation are shown in Figure 1. DSC results show the presence of $\mathrm{Tg}$ in the thermograms which characterizes the PLDLA as an amorphous polymer.

PLDLA membranes remained stable until the $16^{\text {th }}$ week, however, in the $18^{\text {th }}$ and $20^{\text {th }}$ weeks, $\mathrm{Tg}$ reduction was remarkable. This decrease can be the result of polymeric chain cleavage. Given that $\mathrm{Tg}$ is related to the temperature at which the polymeric chains become mobile, the longer the chains, the higher will Tg be. Whereas, smaller chains that are formed during degradation require lower temperatures to produce chain movement which explains Tg decrease.

\subsection{Gel Permeation Chromatography (GPC)}

The determination of molar mass distribution of a polymer is the best way to predict its physical properties, such as stiffness and flexibility, among others, during the degradation process $^{8}$.

Table 1 shows the pondered average molar mass values (Mw) and numerical average molar mass (Mn) according to the hydrolysis time of PLDLA membranes. A decrease in $\mathrm{Mw}$ values was observed after 2 weeks. This decrease was greater from the $16^{\text {th }}$ week $(\mathrm{Mw}=98.156)$ up to the $20^{\text {th }}$ week $(\mathrm{Mw}=8.378)$. These results are typical of the material degradation by hydrolytic cleavage which is characterized by $\mathrm{Mw}$ decrease. The values are consonant with DSC results, which presented evident $\mathrm{Tg}$ reduction in the 18 and 20 week periods.

As degradation builds up, a molar mass decrease was observed in the samples as the result of the breakage of polymeric chains, which could be related to degradation time. The degradation of polyesters, both in vitro and in

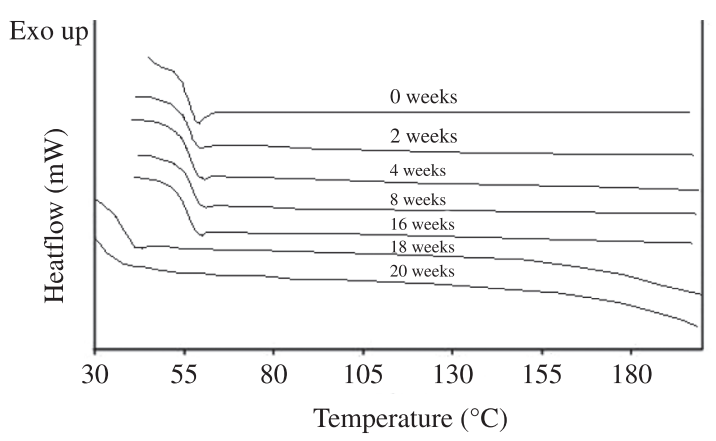

Figure 1. DSC curves of the PLDLA membranes according on the time of degradation in vitro.

Table 1. Results from the GPC according to the time of degradation in vitro.

\begin{tabular}{ccc}
\hline $\begin{array}{c}\text { Time of degradation } \\
\text { (weeks) }\end{array}$ & $\begin{array}{c}\text { Mw } \\
\left(\mathbf{g . m o l}^{-\mathbf{1}}\right)\end{array}$ & $\begin{array}{c}\text { Mn } \\
\left(\mathbf{g . m o l}^{-\mathbf{1}}\right)\end{array}$ \\
\hline 0 & 282,700 & 131,354 \\
2 & 199,011 & 120,246 \\
4 & 184,256 & 132,762 \\
8 & 178,909 & 108,940 \\
16 & 98,156 & 58,265 \\
18 & 10,873 & 3,790 \\
20 & 8,378 & 3,760 \\
\hline
\end{tabular}

$\mathrm{Mw}=$ Ponderal average Molecular Weight, $\mathrm{Mn}=$ Number Average Molecular Weight. 
vivo, was investigated by many authors ${ }^{7}$. Different factors may affect the degradation kinetics. They can be due to chemical composition and configurational structure, processing, molar mass (Mw), polydispersivity (Mw/Mn), environmental conditions, stress and strain, crystallinity, morphology, and chain orientation ${ }^{6}$. Polymers with lower molar mass degrade more quickly than those with a higher molar mass and branched polymers degrade much more quickly than linear polymers.

Stereochemistry has some influence on the polymer final properties. In general, the initial crystallinity level of the polyesters influences the degradation rate since crystalline segments are chemically more stable than amorphous segments, water permeation into the matrix is reduced, and so is the degradation rate ${ }^{6}$. These are the reasons PLDLA has arisen as an alternative to reduce PLLA crystallinity, and a combination of L-lactic and D, L-lactic monomers can be used to produce a copolymer that can be quickly degraded without generating crystalline fragments during the process trial, avoiding severe inflammation ${ }^{1}$.

\subsection{Thermogravimetric analysis (TGA)}

PLDLA membranes were analyzed by means of TGA to evaluate the temperature at the beginning of mass loss (Ti) and the temperature at which the curve derivative is at its maximum rate $(\mathrm{Td})$ in relation to degradation time. Table 2 shows TGA curves for all the samples that present only one mass loss stage, regardless of degradation time, with Ti values at $340{ }^{\circ} \mathrm{C}$ and $\mathrm{Td}$ at $364^{\circ} \mathrm{C}$. Thus, it was possible to observe that $\mathrm{Ti}$ decrease is related to degradation time, since Ti values are lower at the $18^{\text {th }}$ and $20^{\text {th }}$ week periods (Table 2). This behavior is typical of degraded material.

\subsection{In vitro mechanical traction test}

The values of resistance to traction, elasticity module and crack expansion were calculated through the stress $\mathrm{x}$ strain curves obtained by submitting $0,2,4,8$, and 16-week degradation time PLDLA membranes to traction tests.

The mechanical traction test showed that the membranes presented a maximum resistance of about $47.5 \mathrm{MPa}$ and a Young's module of about 2315.71 (about 196.88) MPa. These results are in conformity with the ones found in the literature, respectively $35 \mathrm{MPA}$ and $1900-2400 \mathrm{MPa}^{9-10}$.

PLDLA retained its properties of resistance to traction and elasticity module up to the $8^{\text {th }}$ week of degradation. During the $16^{\text {th }}$ week, these properties presented a reduction showing maximum resistance of 47.5 (about 4) $\mathrm{MPa}$ and Young's module of 2315.71 (around 196.88) MPa as a result of polymeric degradation. Expansion decreased by the $2^{\text {nd }}$ week and remained constant in the course of degradation.

Elasticity module is a property of the material, therefore the comparison between the values obtained for this property module and data on mechanical properties described in the literature is considered to be the best one.

It should be emphasized that, for biomaterials, a high elasticity module value is not always so important, given that during degradation a polymer quickly loses its mechanical properties. However, it is important to bear in mind that the properties required for a material depend on its application.

\subsection{Macroscopic analysis of the in vitro degraded samples}

Through the macroscopic analysis, it was possible to observe that from the $16^{\text {th }}$ week of degradation on there was a reduction in the sample size; and after the $16^{\text {th }}$ and $20^{\text {th }}$ weeks, the membranes were completely degraded presenting a white tone, shown in Figure 2. Nijenjuis et al. ${ }^{11}$ attributed this fact to polymer recrystallization.

\subsection{Scanning Electron Microscopy (SEM)}

The membranes were analyzed by SEM before and after the in vitro degradation process as shown in Figure 3 and Figure 4.

By analyzing SEM micrographs, it is possible to notice membrane degradation related to in vitro degradation time, Figure 3. It can be verified that the morphology of PLDLA before degradation is dense and plain, both on the top surface and on the fractured surface, with no pores and totally compact, Figure 3a, b. Subsequent to only 2 weeks of degradation, some dispersed pores are seen on the membrane surface, Figure 3c. The fracture surface also presented some pores, though fewer, Figure $3 \mathrm{~d}$. This aspect remained until the $8^{\text {th }}$ week of degradation. From the $16^{\text {th }}$ week of degradation on, a clear increase in the amount of pores on the fracture surface is verified, Figure 4d, as well as cracks and fissures, Figure 4c. After 18 weeks of degradation, the material was completely degraded, Figure 4e, preventing the material from fracturing. After 20 weeks, Figure 4f, the

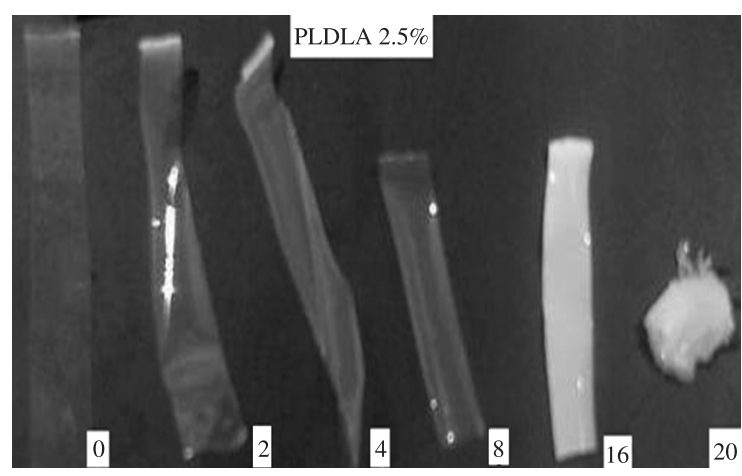

Figure 2. Macroscopy at different times of degradation in vitro.

Table 2. Results obtained by TGA for the membranes of PLDLA depending on the time of degradation in vitro.

\begin{tabular}{ccc}
\hline $\begin{array}{c}\text { Time of degradation } \\
\text { (weeks) }\end{array}$ & $\begin{array}{c}\mathbf{T i} \\
\left({ }^{\circ} \mathbf{C}\right)\end{array}$ & $\begin{array}{c}\mathbf{T d} \\
\left({ }^{\circ} \mathbf{C}\right)\end{array}$ \\
\hline 0 & 340 & 364 \\
2 & 339 & 364 \\
4 & 339 & 364 \\
8 & 339 & 363 \\
16 & 338 & 361 \\
18 & 277 & 309 \\
20 & 250 & 289 \\
\hline
\end{tabular}

$\mathrm{Ti}=$ temperature where it starts the stage of mass loss of "onset", $\mathrm{Td}=$ temperature where the curve is derived from the maximum. 


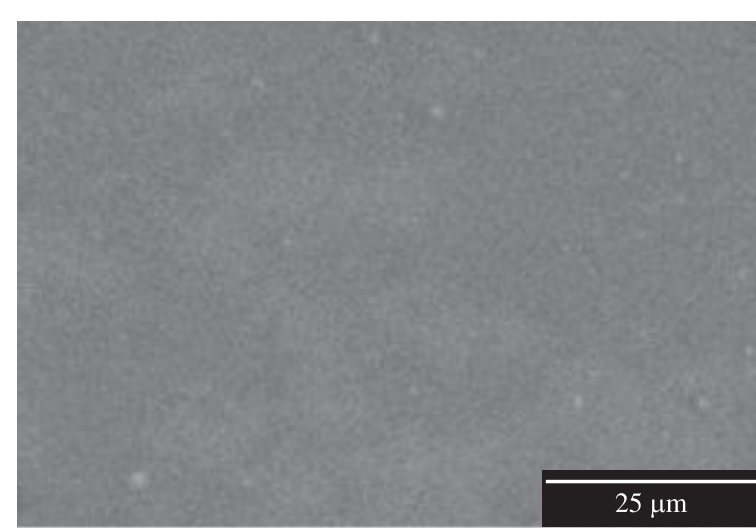

(a)

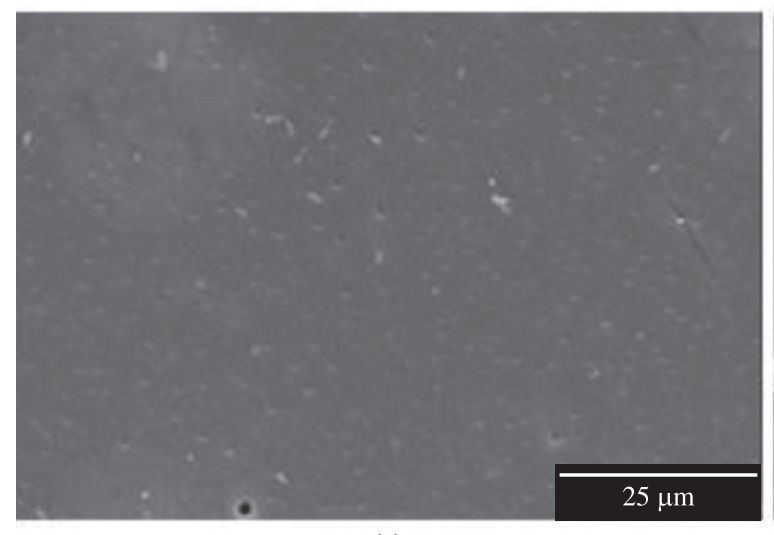

(c)

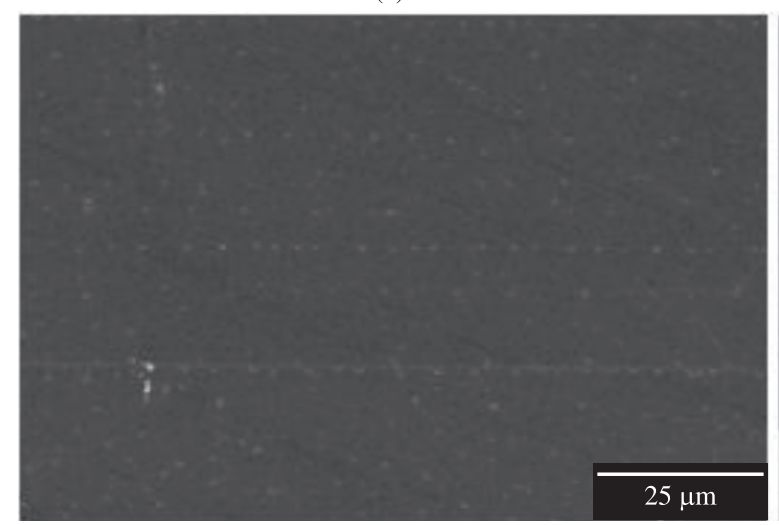

(e)

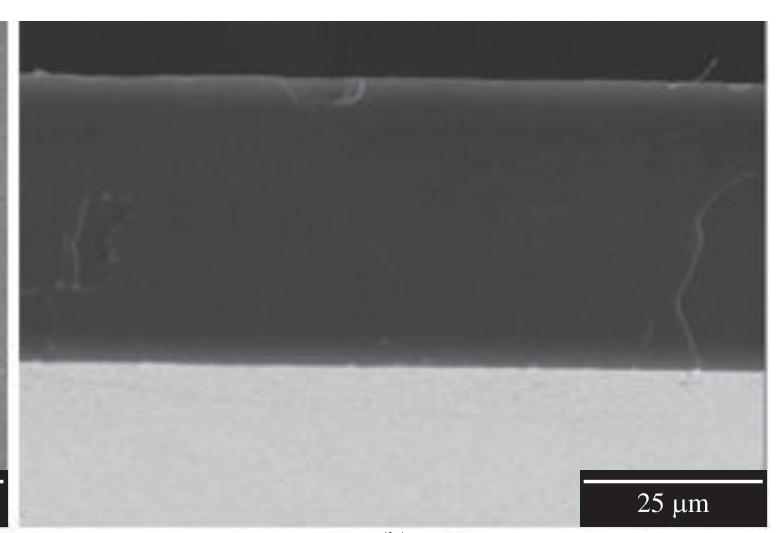

(b)

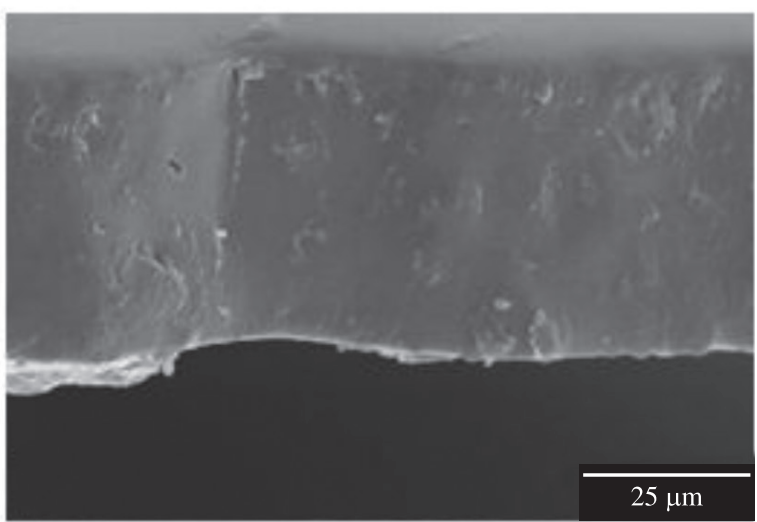

(d)

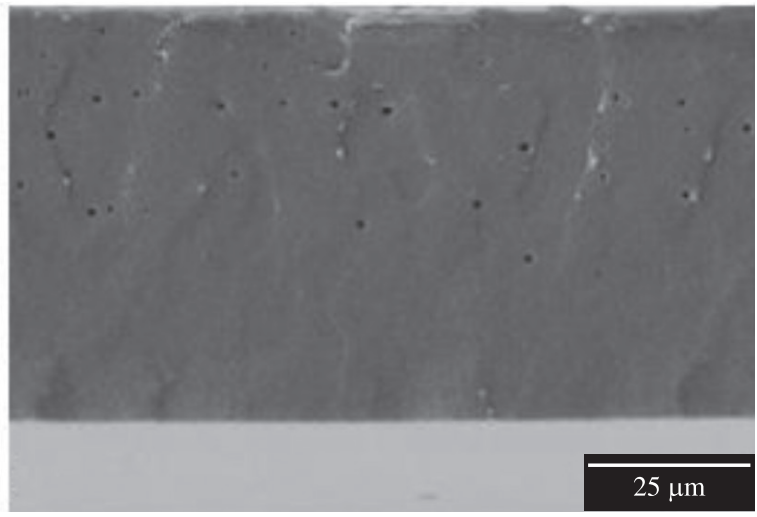

(f)

Figure 3. Scanning Electron Micrographs of membranes of PLDLA depending on the time of degradation in vitro. Areas (left column) and the surface of the fracture (right column) during periods of 0 (a, b), 2 (c, d), 4 (e, f).

degradation process was more intense when compared to the process at its $18^{\text {th }}$ week.

A more detailed study on PLLA degradation, described by Vert et al. ${ }^{12}$, showed that the polymer degrades in a heterogeneous form, and this degradation is faster in amorphous environments than in crystalline ones. It is also faster inside the membrane than on the surface due to acid autocatalysis. In vitro studies allow the observation of preferential internal degradation, which mimics the physiological medium. The polymer is immersed in a watery medium where water absorption occurs and hydrolytic cleavage of ester bonds begins, which cause a molar mass reduction. At first, the degradation is faster on the surface than in the center due to the water absorption gradient. The products of degradation are formed both on the surface and in the center, but the ones near the surface dissolve more easily in the medium, since the ones inside should be spread throughout the mass. Thus, the concentration of carboxylic acid groups is greatly augmented in the interior than on the surface of the membrane, catalyzing degradation ${ }^{9}$.

The increase of porosity is directly related to the degradation time. This technique allowed better observation of the membrane degradation process, which 


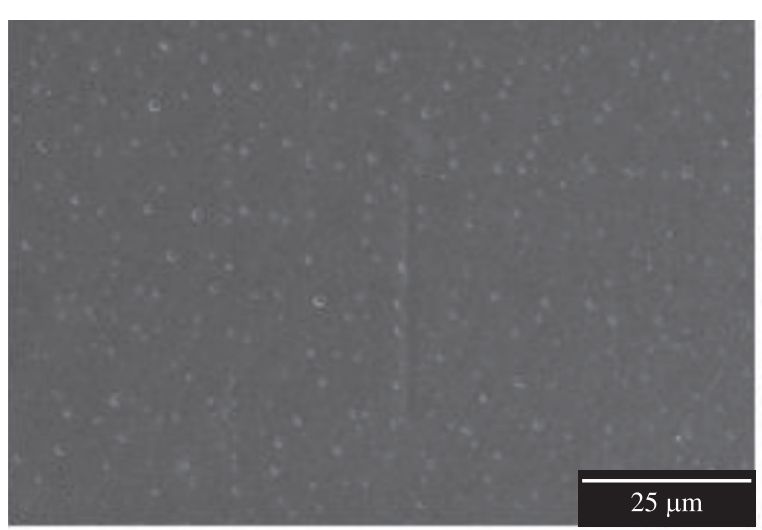

(a)

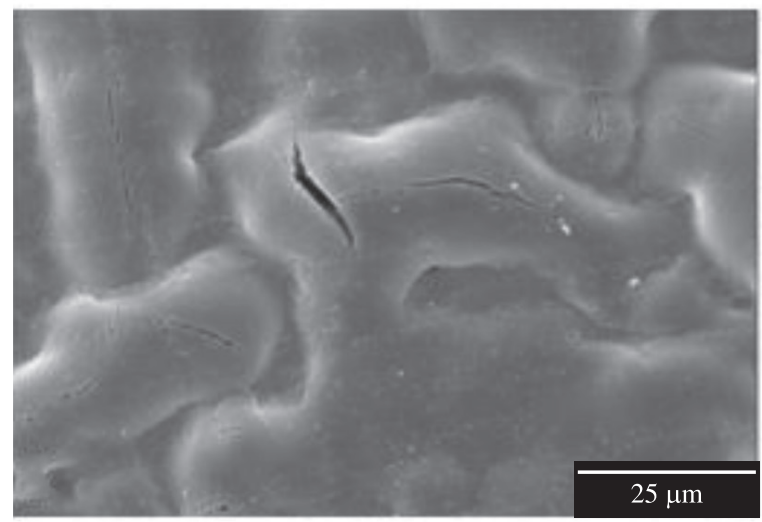

(c)

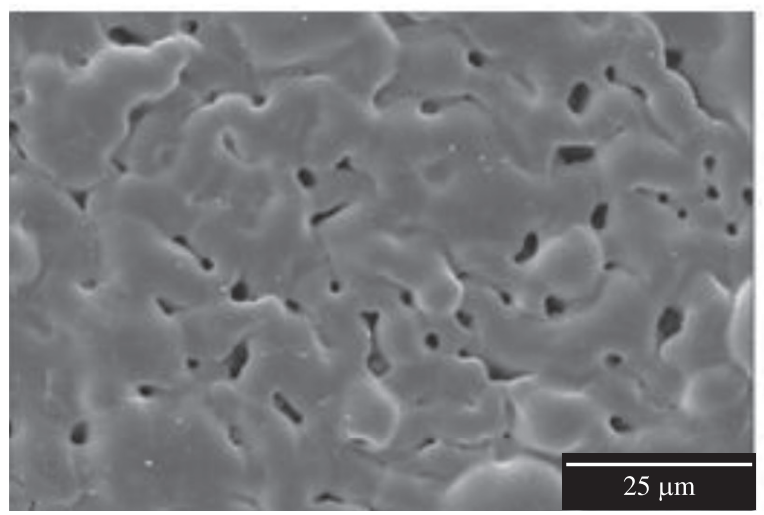

(e)

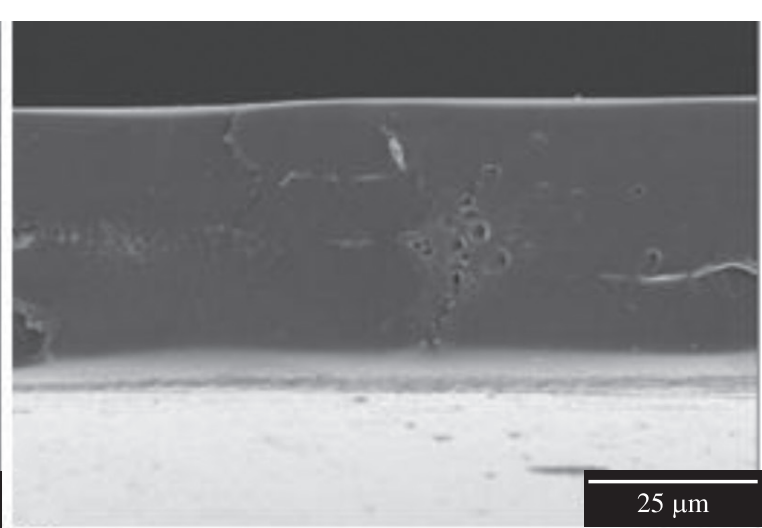

(b)

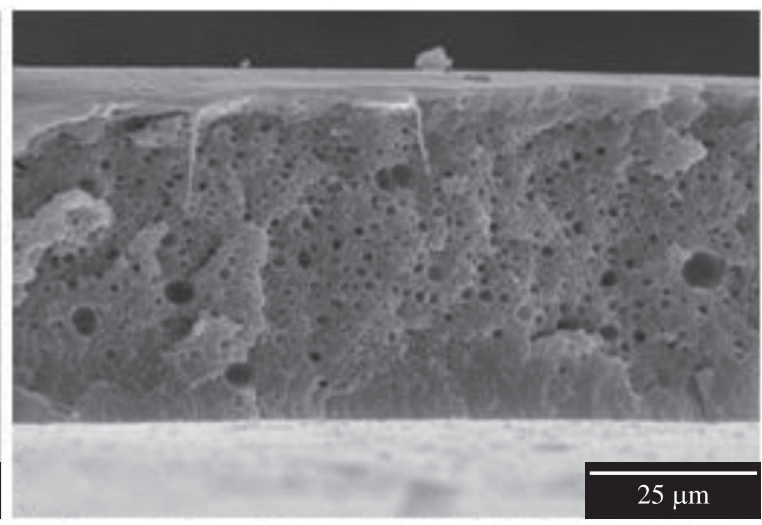

(d)

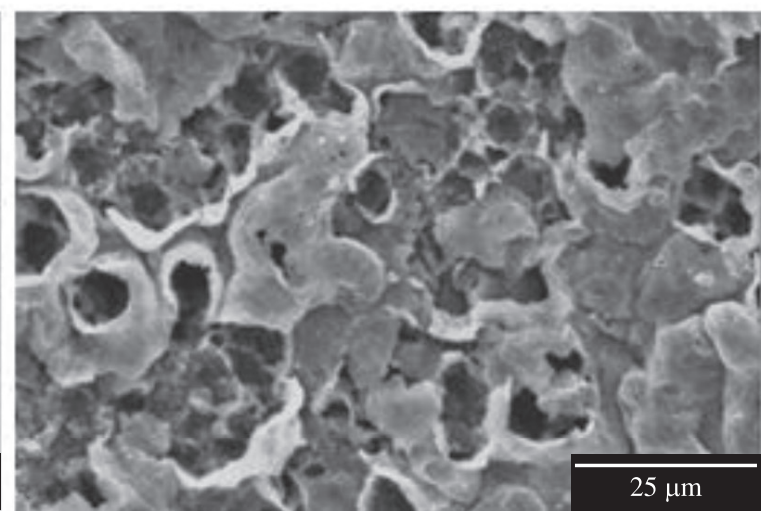

(f)

Figure 4. Scanning Electron Micrographs of membranes of PLDLA depending on the time of degradation in vitro. Areas (left column) and the surface of the fracture (right column) during periods of $8(a, b), 16(c, d)$, and only surface 18, 20 weeks (e, f).

is characterized by the development of fractures and pores on the polymer.

\section{Conclusions}

This study has confirmed that PLDLA membranes which were prepared by the solvent evaporation technique have an amorphous nature.

After the membranes were submitted to in vitro degradation, it was verified that their degradation was directly related to the time they were immersed in buffer solution. In addition, the degradation process of PLDLA starts at the $8^{\text {th }}$ week and is macroscopically degraded 16 weeks later, with membranes presenting variations in thermal, mechanical and morphologic properties. SEM micrographs showed, at first, that the membranes were morphologically dense with the surge of pores as the result of the degradation process.

Finally, PLDLA membranes obtained by means of solvent evaporation, besides presenting excellent potential as temporary implantation given their degradation characteristics, for instance, their application as prostheses for nervous regeneration, have also been shown to be feasible for in vivo applications. 


\section{References}

1. Baraúna GS, Pierucci A, Oliveira AD, Duarte MAT and Duek EAR. Estudo da degradação "in vivo" de poli(L-co-D,L-ácido láctico) aplicado como prótese para regeneração nervosa periférica. Matéria. 2007; 12(2):298-306.

2. Barbanti SH, Zavaglia CAC and Duek EAR. Polímeros bioreabsorvíveis na engenharia de tecidos. Polímeros. 2005; 15(1):13-21. http://dx.doi.org/10.1590/ S0104-14282005000100006

3. Tsuruga E, Takita H, Itoh H, Wakisaka $\mathrm{Y}$ and Kuboki Y. Pore Size of Porous Hydroxyapatite as the CellSubstratum Controls BMP-Induced Osteogenesis. Journal of Biochemistry. 1997; 121(2):317-24. PMid:9089406. http:// dx.doi.org/10.1093/oxfordjournals.jbchem.a021589

4. Bergsma JE, De Bruijn WC, Rozema FR, Bos RRM and Boering G. Late degradation tissue response to poly(-lactide) bone plates and screws. Biomaterials. 1995; 16(1):25-31. http:// dx.doi.org/10.1016/0142-9612(95)91092-D

5. Bessho K, Iizuka T and Murakami K-I. A bioabsorbable polyL-lactide miniplate and screw system for osteosynthesis in oral and maxillofacial surgery. Journal of Oral and Maxillofacial Surgery. 1997; 55(9):941-5. http://dx.doi.org/10.1016/S02782391(97)90065-3

6. Rezwan K, Chen QZ, Blaker JJ and Boccaccini AR. Biodegradable and bioactive porous polymer/inorganic composite scaffolds for bone tissue engineering.
Biomaterials. 2006; 27(18):3413-31. PMid:16504284. http:// dx.doi.org/10.1016/j.biomaterials.2006.01.039

7. Holland SJ, Tighe BJ and Gould PL. Polymers for biodegradable medical devices. 1. The potential of polyesters as controlled macromolecular release systems. Journal of Controlled Release. 1986; 4(3):155-80. http://dx.doi.org/10.1016/01683659(86)90001-5

8. Rowland SM and Striegel AM. Characterization of Copolymers and Blends by Quintuple-Detector Size-Exclusion Chromatography. Analytical Chemistry. 2012; 5(16). [Epub ahead of print]

9. Middleton JC and Tipton AJ. Synthetic biodegradable polymers as orthopedic devices. Biomaterials. 2000; 21(23):2335-46. http://dx.doi.org/10.1016/S0142-9612(00)00101-0

10. Yang S, Leong K-F, Du Z and Chua C-K. The Design of Scaffolds for Use in Tissue Engineering. Part I. Traditional Factors. Tissue Engineering. 2001; 7(6):679-89. PMid:11749726. http://dx.doi. org/10.1089/107632701753337645

11. Nijenhuis AJ, Grijpma DW and Pennings AJ. Highly crystalline as-polymerized poly(1-lactide). Polymer Bulletin. 1991; 26(1):71-7. http://dx.doi.org/10.1007/ BF00299350

12. Vert M, Li SM, Spenlehauer G and Guerin P. Bioresorbability and biocompatibility of aliphatic polyesters. Journal of Materials Science: Materials in Medicine. 1992; 3(6):432-46. http://dx.doi.org/10.1007/BF00701240 